\title{
Consumers' Responses to Table Spacing in Restaurants
}

\author{
By Stephani K. A. Robson', Sheryl E. Kimes', \\ Franklin D. Becker', and Gary W. Evans'
}

\begin{abstract}
Having adequate personal space is an important aspect of users' comfort with their environment. In a restaurant, for instance, spatial intrusion by others can lead to avoidance responses such as early departure or a disinclination to spend. A web-based survey of more than 1,000 Americans elicited behavioral intentions and emotional responses to a projected restaurant experience when parallel dining tables were spaced at six, twelve, and twenty-four inches apart under three common dining scenarios. Respondents strongly objected to closely spaced tables in most circumstances, particularly in a "romantic" context. Not only did the respondents react negatively to tightly spaced tables but they were generally disdainful of banquettestyle seating, regardless of table distance. The context of the dining experience (e.g., a business lunch, a family occasion) is likely to be a key factor in consumers' preferences for table spacing and their subsequent behaviors. Gender was also a factor, as women were much less comfortable than men in tight quarters. The findings are clear but the implications for restaurateurs are not, because a tight table arrangement has been demonstrated to shorten the dining cycle without affecting spending. However, diners may be less likely to return to a restaurant with uncomfortable table spacing.
\end{abstract}

\section{Keywords}

personal space, restaurant design, consumer behavior, restaurant table spacing

Most people think that full-service restaurants are in the business of selling food, but that is only one aspect of the experience. Another way to consider the restaurant industry is as one that rents out space to diners: when guests occupy a table, they pay rent in the form of food and drink purchases. For most restaurants, there is no direct connection between this "rent" and the dimensions of the space occupied. Parties of five might be wedged into a table for four, or a couple may be seated at that same four-top, depending on the situation. Likewise, table spacing varies considerably from restaurant to restaurant. Many operators attempt to maximize their potential revenues by reducing the amount of space between tables, especially since this is one of the few ways that most fullservice restaurants can increase capacity without building alterations. A banquette that can accommodate eight parties of two when tables are spaced 18 inches $(46 \mathrm{~cm})$ apart is able to support an additional three parties of two if the spacing is reduced to 6 inches $(15 \mathrm{~cm})$. Assuming an average check of $\$ 30$, the additional capacity afforded by tighter table spacing could translate into a 37.5-percent increase in revenues from this banquette without any increase in the amount of dining room space. Thus, assuming customers will agree to sit in such closely spaced tables, the customer "rent" that the operator receives per square foot has the potential to increase dramatically.
Revenue management (RM) strategies for restaurants focus on maximizing capacity (Kimes et al. 1998) or matching table mix to customer mix (Kimes 2004). But current RM practice generally does not take into account the space that each table occupies (Rohlfs 2009). In an effort to maximize capacity, many restaurant operators make what they hope is the most profitable use of dining room space by packing in as many tables as codes will allow. While this approach to increasing capacity may appear to be a valid strategy, a significant concern is that close table spacing may generate dissatisfaction because of reduced personal space. A recent online survey of British consumers revealed that 64 percent of respondents found closely spaced tables to be detrimental to the dining experience (Smithers 2010).

The study presented here investigates how American consumers view restaurant table spacing practices. In particular, we examine whether tight table spacing influences guest attitudes and preferences. What follows is a brief review of the literature as it relates to personal space and privacy in

'Cornell University, Ithaca, NY

Corresponding Author:

Stephani K. A. Robson, Cornell University,

School of Hotel Administration, 255 Statler Hall, Ithaca, NY I4853

Email: skr4@cornell.edu 
public settings, accompanied by a summary of a U.S.-based survey that sought reactions to images of restaurant tables set at different distances under three dining scenarios. The findings build on what is known about proxemic behavior in service settings and is the first study to specifically evaluate table spacing in restaurants.

Spacing preferences are often moderated by cultural mores (Hall 1966; Kaya and Weber 2003), and this study is also the first to compare white, Asian, and Hispanic responses to table spacing to determine whether these differences might translate into variations in seating layout for restaurants targeting these markets. Our findings are intended to help restaurant operators and designers to create dining environments that use space well and maximize potential returns to the operator without diminishing the guest experience.

\section{Personal Space in Dining Environments}

The concept of personal space is well established (Hall 1966), but the amount of personal space a person needs varies according to individual, situation, and culture. People usually need greater personal space with strangers, and real discomfort occurs if someone violates that space without good reason (Hall 1966). However, personal space boundaries are not uniform in shape. They tend to be broader directly in front of and behind a person and narrower on either side (Hayduk 1981), leading to increased sensitivity to encroachments from the front or rear than from the side (Kaya and Erkip 1999).

Tight personal space, 18 inches (45 cm) or less (Hall 1966), reduces privacy and increases stress if the person nearby is not an intimate (Altman 1975), and the resulting discomfort can generally only be alleviated by either increasing interpersonal distance when conditions allow (Argyle and Dean 1965; Bailenson et al. 2001) or by leaving the environment (Baum and Valins 1977).

However, tight personal space does not always result in discomfort, since individual and situational differences moderate responses to tight interpersonal spacing. Sex, age, group size and composition, and cultural affiliation have all been shown to influence spatial preferences and behaviors (see Hayduk 1983 for a detailed summary). In general, men and older people appear to prefer more interpersonal distance. Larger groups tend to command greater personal space per person than do smaller ones (Knowles et al. 1976). Interacting with friends or relatives requires less personal space (Sinha and Nayyar 2000), whereas disequilibrium in status between participants in a group increases spatial boundaries (Hayduk 1983). Also influencing proxemic behaviors is cultural affiliation, which is often equated with nationality or ethnicity in observational research despite conceptual differences among these terms (Clark 1990; Lee 2000). People in Asia, the Mediterranean, and Latin America often adopt closer interpersonal distances than do those from North America or Northern Europe (Hall 1966; Evans et al. 2000).

Situational context profoundly affects privacy needs. Potentially stressful situations such as dining by oneself in public or being interviewed during a meal require greater privacy (Barash 1972; Robson 2008), and even the size of the environment can influence how close individuals will sit: the larger the space, the closer its occupants will typically gather (Sommer 1965). Familiarity with high-density situations, either from past experience or from descriptive information received ahead of time, may affect reactions to reduced personal space (Baum, Fisher, and Solomon 1981). Those who live in crowded urban areas tend to be more comfortable with reduced personal space but may react more forcefully when spatial norms are not respected (Kaya and Weber 2003).

In some conditions, reduced personal space may actually be desirable. For example, tight quarters in a busy nightclub may be more exciting and arousing (Grazian 2007). Arousal can benefit restaurants if applied correctly. The right degree of arousal can encourage exploration, lengthen the amount of time spent, and increase spending (Mehrabian and Russell 1974; Donovan et al. 1994), and the appropriate degree of arousal in a service setting enhances satisfaction (Wirtz, Mattila, and Tan 2000; Mattila and Wirtz 2006).

Understanding the desired degree of personal space is key for effective restaurant design and management, but there is little research on guest preferences or behaviors regarding restaurant seating. Guests appear to prefer restaurants that have other patrons present but not in such number or proximity that conversations cannot be conducted easily or that personal boundaries are violated (Tse, Sin, and Yim 2002; Andersson and Mossberg 2004). Customers prefer tables that offer the most control over personal space, generally through the provision of some kind of physical feature that separates tables from others (Robson 2008). When dining with friends and family, consumers tend to choose tables next to a window while tables in a corner are strongly preferred when the occasion is more formal. This desire for personal space may explain the popularity of booth seating in many restaurants (Sommer 1959; Desor 1972; Dale 1982).

\section{Research Question}

While it is clear that diners want adequate personal space, what is "adequate" in this context has not been clearly established. Most research that examines seating preferences and behaviors has looked at the distance between individual chairs or the relative position of seats around a single table, rather than the distance between tables (Sommer 1965, 1969; Mehrabian and Diamond 1971; Patterson et al. 1979; Pedersen 1994). The study presented here gives insights into how guests perceive specific table distances during particular dining occasions, and how those perceptions translate into attitudes and preferences. In addition to providing empirical evidence for the importance 
of space as a component of capacity, and expanding the understanding of restaurant seating behavior, our intention is to provide the restaurant industry with guidance regarding appropriate table distances for full-service dining operations.

One particular concern for restaurants with tight table spacing is what Mehrabian and Russell (1974) call "avoidance behavior." If having less personal space reduces a guest's ability to control privacy, then it is possible that diners may leave prematurely, reduce their spending, and develop negative attitudes toward the restaurant. One study has shown that table types that offer guests reduced psychological comfort appear to reduce dining duration (Kimes and Robson 2004), and it may be that shorter stays will occur when guests are seated in close proximity to adjacent tables.

\section{Method}

For this study, we used a two-part web-based questionnaire to elicit guest responses to images of restaurant tables at varying distances. The first part of the survey asked respondents to report their gender, age, ethnicity, place of residence (urban, suburban, rural), restaurant use frequency, and whether they had work experience in the restaurant industry. These last three variables were selected to help identify respondents who may be more familiar with close table distances, but all the factors are potential moderators of restaurant table preferences. We did not ask about country of birth or citizenship.

The second part of the survey measured emotional, intentional, and anticipated behavioral reactions to one of three images of tables for two placed at a distance of 6,12 , or 24 inches away from each other. The questions invoked one of three dining scenarios: dining for business purposes ("Business"), dining with a friend ("Friend"), and dining while on a date ("Romantic"). These three scenarios were selected to represent realistic dining occasions and also to vary the level of stress suggested by the scenarios. The three distances selected were derived from three sources: Hall's work on preferred interpersonal distances for intimates and acquaintances (Hall 1966), an earlier study that identified preferred distances for parallel tables for two (Robson et al. 2010), and a review of floor plans of recently constructed restaurants in hospitality design publications. The 6-inch distance represented the close phase of Hall's "intimate" distance and is also typical of the spacing adopted for banquette seating in many urban restaurants in high-cost markets such as New York City. Spacing of 24 inches was selected to represent the close phase of Hall's "personal" distance and to reflect spacing preferences determined by Robson et al. (2010). The 12-inch distance was chosen because it was close to the mean inter-table distance identified from the plan review and served as a useful intermediate point between the other two distances selected for the study. Photographs showing a typical restaurant banquette with empty tables spaced at one of the three selected distances served as visual prompts for the survey (Exhibit 1).

\section{Exhibit 1: \\ Example of visual prompt (6-inch table spacing shown)}

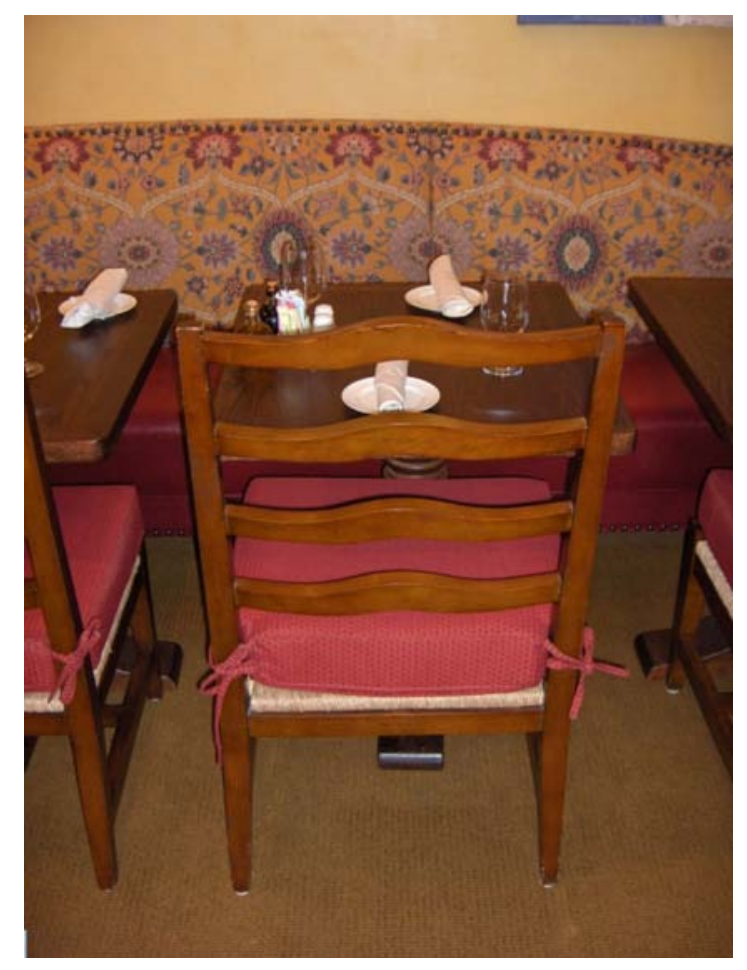

Respondents were randomly assigned to one of nine combinations of scenarios and table-spacing images and asked to respond to a series of thirty-two statements that solicited their emotional and behavioral responses to specific distances. Responses to each statement were measured on a standard Likert-type scale ( 1 = strongly disagree, 7 = strongly agree $)$. Twelve statements related to emotional responses and were selected from the Stress Arousal Check List (SACL), a survey instrument demonstrated to accurately reflect respondent stress and arousal and to clearly differentiate between these constructs (King, Burrows, and Stanley 1983). An additional sixteen items that tested the constructs of perceived control (Hui and Bateson 1991), physical and sensory privacy (Altman 1975), goal blocking (Sundstrom 1975), and general comfort were designed to measure behavioral and intentional responses to the seating. The survey also included a single measure of perceived crowding to serve as a manipulation check.

All survey items were pretested using a convenience sample to check for validity and reliability. For this test, we asked ten individuals of varying ages, ethnicities, and locations to distribute a link to the web-based pilot survey to their own contacts via email, resulting in a sample of 282 valid responses. Exploratory factor analysis using principal components extraction and varimax rotation resulted in a reduction 
Exhibit 2:

Factor Analysis of Retained Pretest Survey Items

\begin{tabular}{lcc}
\hline & \multicolumn{2}{c}{ Component } \\
\cline { 2 - 3 } & I & 2 \\
\hline $\begin{array}{l}\text { Sitting at this table, I would feel like the } \\
\text { restaurant cares about me }\end{array}$ & 0.826 & -0.153 \\
$\begin{array}{l}\text { Sitting at this table, I would have the kind } \\
\text { of experience I want }\end{array}$ & 0.754 & -0.206 \\
$\begin{array}{l}\text { Sitting at this table, I would have an } \\
\text { exciting meal experience }\end{array}$ & 0.725 & -0.166 \\
$\begin{array}{l}\text { Sitting at this table, I would feel like a VIP } \\
\text { Sitting at this table, I would disturb the }\end{array}$ & 0.672 & -0.060 \\
$\begin{array}{l}\text { next table if I had to get up } \\
\text { Sitting at this table, I would be overheard }\end{array}$ & -0.024 & 0.75 I \\
$\begin{array}{l}\text { by other diners } \\
\text { Sitting at this table, I would feel like I was } \\
\text { being watched }\end{array}$ & -0.307 & 0.726 \\
$\begin{array}{l}\text { Sitting at this table, I would feel exposed } \\
\text { Interitem reliability (Cronbach's alpha) }\end{array}$ & -0.422 & 0.695 \\
\hline
\end{tabular}

in the number of seating response items in the survey from sixteen to eight (Exhibit 2), but all other items were retained.

Responses to the emotional items from the SACL were combined based on King, Burrows, and Stanley's scoring to create summary scores for the constructs of stress and arousal, and the remaining responses were combined to form summary scores for perceptions of control and comfort (King, Burrows, and Stanley 1983). These summary scores provided a way to differentiate among the four major constructs being studied and simplified further analysis. The final survey was distributed via a web link to a diverse national sample obtained from a professional sampling company.

\section{Results}

We closed the survey access shortly after receiving slightly more than 1,000 responses, and ended up with 1,013 valid responses. Demographic and other sample characteristics are summarized in Exhibit 3. The sample was well balanced by gender and relatively well balanced by residence, but had notable imbalances across age groups, ethnicities, and dining frequency. About one-third of the sample had worked in a restaurant at some time, which is slightly lower than the national average (National Restaurant Association 2010).

Random assignment of respondents to table spacing distances and scenarios resulted in generally well-balanced samples of at least ninety valid responses for each of the nine Spacing $\times$ Scenario conditions. Confirmatory factor analysis on the reaction and emotional scales using principal component extraction and varimax rotation showed that all variables loaded as expected and had acceptable reliability results, as summarized in Exhibit 4. The reaction scales loaded well on
Exhibit 3:

Demographics of Survey Respondents

\begin{tabular}{|c|c|c|}
\hline Gender & $n$ & $\%$ \\
\hline Male & $46 I$ & 45.5 \\
\hline Female & 537 & 53.0 \\
\hline No response & 15 & 1.5 \\
\hline \multicolumn{3}{|l|}{ Age (years) } \\
\hline Under 21 & 62 & 6.1 \\
\hline $21-35$ & 234 & 23.1 \\
\hline $36-50$ & 319 & 31.5 \\
\hline$>50$ & 391 & 38.6 \\
\hline No response & 7 & 0.7 \\
\hline \multicolumn{3}{|l|}{ Ethnicity } \\
\hline White & 821 & 81.1 \\
\hline Black & 74 & 7.3 \\
\hline Hispanic (any race) & 44 & 4.3 \\
\hline Asian & 33 & 3.3 \\
\hline Other & 37 & 3.7 \\
\hline No response & 4 & 0.4 \\
\hline \multicolumn{3}{|l|}{ Residence } \\
\hline Major city & 182 & 18.0 \\
\hline Smaller city & 257 & 25.4 \\
\hline Suburban area & 340 & 33.6 \\
\hline Rural area & 230 & 22.7 \\
\hline No response & 4 & 0.4 \\
\hline \multicolumn{3}{|l|}{ Dining frequency } \\
\hline More than three times per week & 63 & 6.2 \\
\hline One to two times per week & 198 & 19.5 \\
\hline One to two times per month & 340 & 33.6 \\
\hline Less than one time per month & 319 & 31.5 \\
\hline Don't know/no response & 93 & 9.2 \\
\hline \multicolumn{3}{|l|}{ Experience in restaurants } \\
\hline Yes & 392 & 38.7 \\
\hline No & 618 & 61.0 \\
\hline No response & 3 & 0.3 \\
\hline
\end{tabular}

two factors, which were grouped as Pleasure and Privacy. The emotional variables loaded very clearly and reliably into stress and arousal factors, providing further evidence of the efficacy of the King, Burrows, and Stanley (1983) measure for distinguishing between these two types of response to environmental conditions.

Exhibits 5 through 10 summarize the survey results by distance. For all of the pleasure, stress, control, and comfort variables and for all but one of the privacy variables, there was a statistically significant difference between responses to tables set 6 inches apart and those at 12 inches or 24 inches. Means varied in the expected directions. None of the arousal variables was significantly different across the various distances. Close table spacing made respondents feel less private, more crowded, less likely to have a positive meal experience, and more dissatisfied with the table to which they were 


\section{Exhibit 4:}

Confirmatory Factor Analysis of Survey Items

\begin{tabular}{lcc}
\hline Reaction Items & $\begin{array}{c}\text { Component I } \\
\text { (Pleasure) }\end{array}$ & $\begin{array}{c}\text { Component 2 } \\
\text { (Privacy) }\end{array}$ \\
\hline Exciting & 0.873 & -0.1101 \\
Cares & 0.871 & -0.125 \\
Experience & 0.853 & -0.124 \\
VIP & 0.840 & -0.159 \\
Watched & -0.127 & 0.845 \\
Overheard & -0.115 & 0.840 \\
Disturb & -0.123 & 0.808 \\
Exposed & -0.116 & 0.753 \\
Cronbach's alpha & 0.892 & 0.835 \\
\hline & Component I & Component 2 \\
Emotional Items & $($ Arousal) & $($ Stress) \\
\hline Lively & 0.863 & -0.164 \\
Influential & 0.844 & -0.128 \\
Active & 0.835 & -0.080 \\
Vigorous & 0.810 & -0.024 \\
In control & 0.807 & -0.296 \\
Contented & 0.758 & -0.281 \\
Comfortable & 0.758 & -0.389 \\
Passive & 0.564 & 0.217 \\
Tense & -0.128 & 0.873 \\
Distressed & -0.103 & 0.844 \\
Uptight & -0.101 & 0.835 \\
Worried & 0.006 & 0.800 \\
Bothered & -0.256 & 0.788 \\
Crowded & -0.138 & 0.771 \\
Cronbach's alpha & 0.913 & 0.908 \\
\hline & &
\end{tabular}

\section{Exhibit 5:}

Comparison of survey items by table spacing: Pleasure

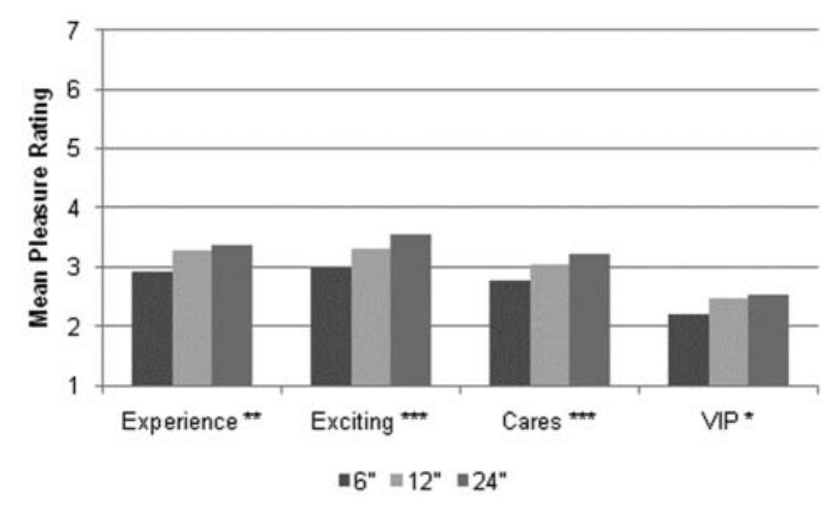

$*_{p}<.05 ; * * p<.01 ; * * * p<.001$.

\section{Exhibit 6:}

Comparison of survey items by table spacing: Privacy

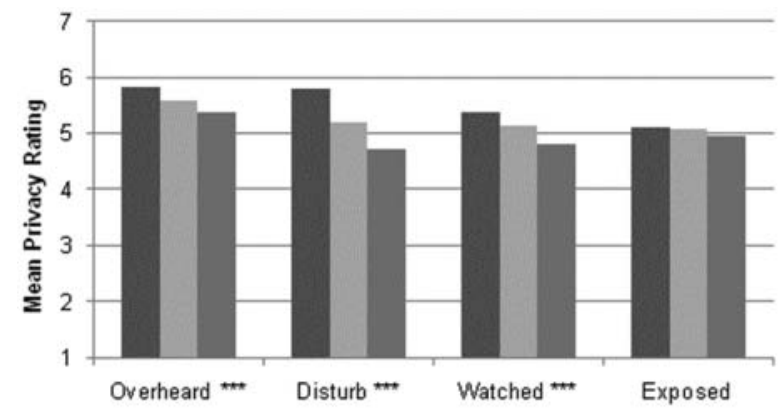

" $6 "=12^{\prime \prime}=24^{\prime \prime}$

$* * * p<.001$.

Exhibit 7:

Comparison of survey items by table spacing: Seating preferences

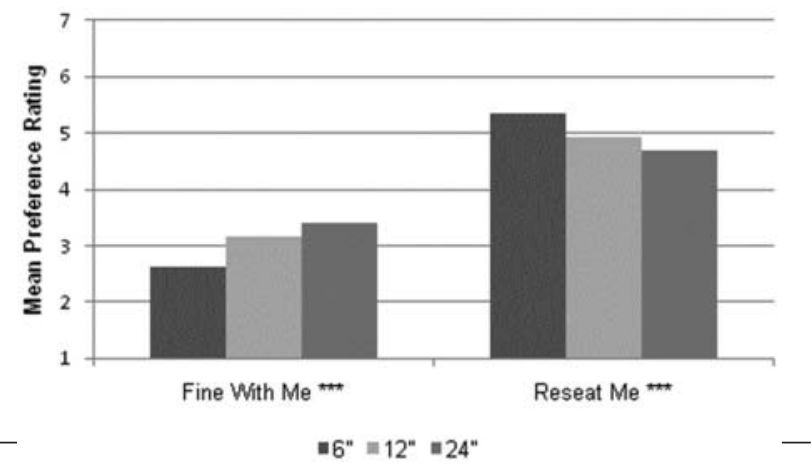

$* * * p<.001$.

\section{Exhibit 8:}

Comparison of survey items by table spacing: Stress

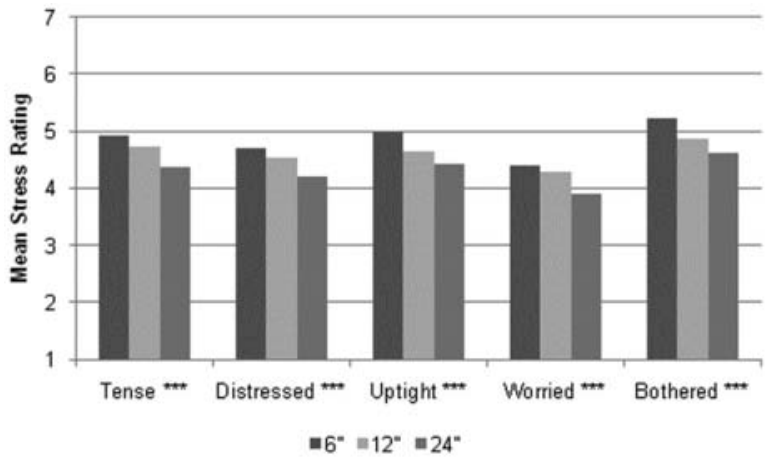

$* * * p<.001$. 


\section{Exhibit 9:}

\section{Comparison of survey items by table spacing: Arousal}

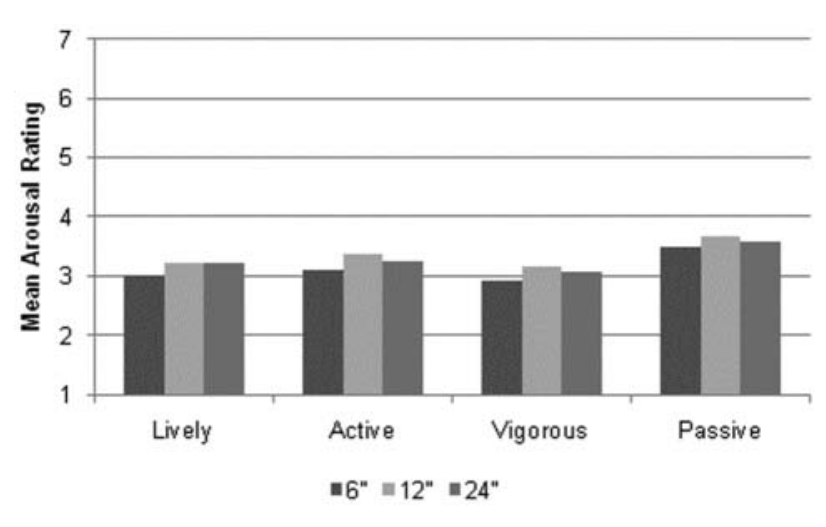

\section{Exhibit 10:}

Comparison of survey items by table spacing: Control and comfort

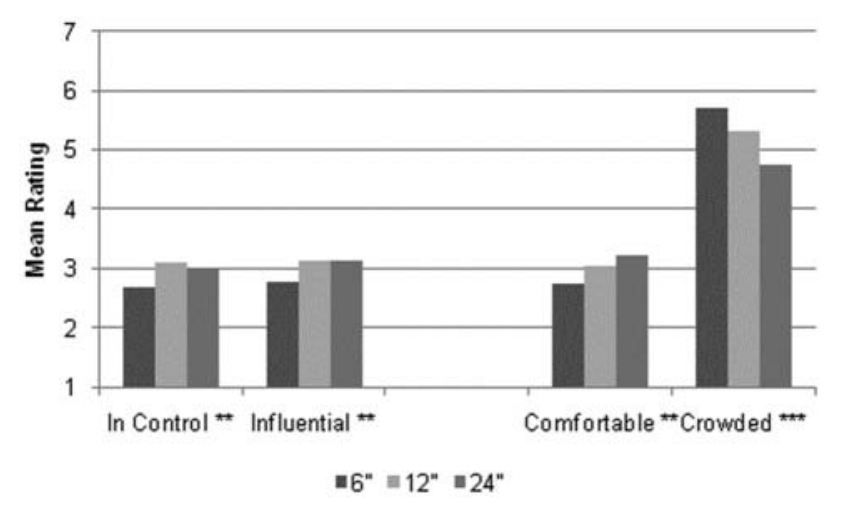

$* * p<.01 ; * * * p<.001$.

assigned. Furthermore, patrons presented with tables spaced 6 inches apart were more concerned with disturbing others or being overheard by others during the meal (Exhibit 6).

Stress responses (Exhibit 8) varied significantly by table distance $(F=11.994, d f=2, p<.000)$. Tables that were pictured at 6 inches apart rendered a mean stress score of 24.12 , while the score for tables pictured at 12 inches was 23.06) and the stress score at 24 inches was 21.46. As we mentioned, arousal scores (Exhibit 9) were not significantly different for the three table spacing conditions at the .05 level $(F=2.842, d f=2, p=.059)$, but feelings of control $(F=7.483$, $d f=2, p=.001)$ and comfort $(F=18.031, d f=2, p<.000)$ were markedly lower for closely spaced tables than they were at wider spacing (Exhibit 10).

The correlations among the four emotional summary scores conformed to the theoretical relationships among stress, arousal, control, and comfort. All correlations were significant at the $p<.01$ level. Stress scores were negatively correlated with arousal scores $(r=-.239)$ and with feelings of control $(r=-.341)$ and comfort $(r=-.630)$. Strong positive correlations were identified between arousal and comfort $(r=.787)$, arousal and control $(r=.627)$, and comfort and control $(r=.730)$, providing further evidence that stress and arousal are distinct constructs and that guests may consider moderate levels of arousal to be positive.

The dining scenario appeared to be important when assessing satisfaction with a given table distance (Exhibits 11 through 14). This effect was most pronounced for the romantic scenario: respondents who were asked to envision being on a date were strongly negative when presented with closely adjacent tables, expressing significantly more stress $(F=8.278$, $d f=4, p<.000)$, less control $(F=4.587, d f=4, p=.011)$, and more discomfort $(F=14.713, d f=4, p<.000)$ at the 6-inch distance than at the 12- and 24-inch spacing. Dining while on business did not appear to affect responses to tight table spacing except in terms of comfort $(F=3.629, d f=4, p=.028)$, whereas dining with a friend prompted modest stress $(F=3.817, d f=4$, $p=.023)$ and $\operatorname{discomfort}(F=3.991, d f=4, p=.019)$ for tight spacing. Close table spacing had no significant effect on arousal or perceived control in a business scenario.

Stress, arousal, control, and comfort were all moderated by gender. In general, women expressed significantly more stress $(t=-4.024, p<.000)$, less control $(t=4.564, p<.000)$, and greater discomfort $(t=5.292, p<.000)$ than men, while men felt more arousal $(t=3.078, p<.002)$ than women at each distance. Even at the relatively generous 24 -inch spacing, women were significantly more uncomfortable than men in every scenario. There were no significant interactions between gender and table spacing.

Degrees of stress, arousal, control, and comfort varied significantly but not consistently by age group. (Because the number of respondents under 21 was substantially lower than that of the other three age groups tested, this younger group was excluded from any age-related analyses.) Stress levels were not significantly different by age group except at the 24-inch spacing, where younger patrons expressed slightly higher stress levels $(F=2.716, d f=2, p=.045)$. Younger respondents were more aroused at the 12-inch distance than other age groups $(F=6.065, d f=2, p=.001)$ and also appeared to feel more in control $(F=5.700, d f=2, p=.001)$ and marginally more comfortable $(F=3.172, d f=2, p=.025)$ at the 6-inch spacing than did those older than age 35 . Surprisingly, all age groups felt more in control at the 12 -inch distance than at the 6- or 24-inch spacing. In terms of comfort, older respondents expressed diminished comfort as table spacing decreased, with respondents older than 50 indicating the greatest degree of discomfort at the 6-inch distance and the highest degree of comfort with tables set 24 inches apart. There were no significant interactions between age and spacing. 


\section{Exhibit 11:}

Stress responses by table spacing and scenario

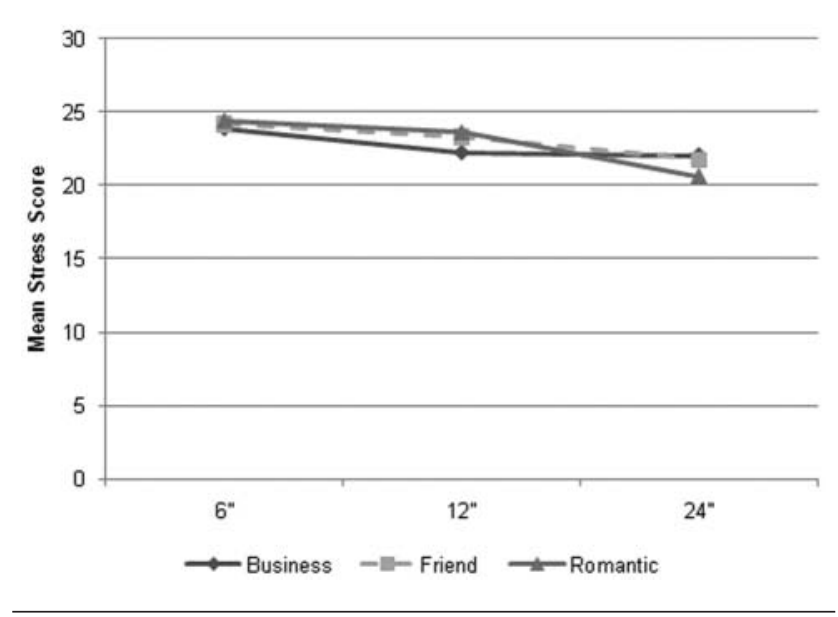

Exhibit 12:

Arousal responses by table spacing and scenario

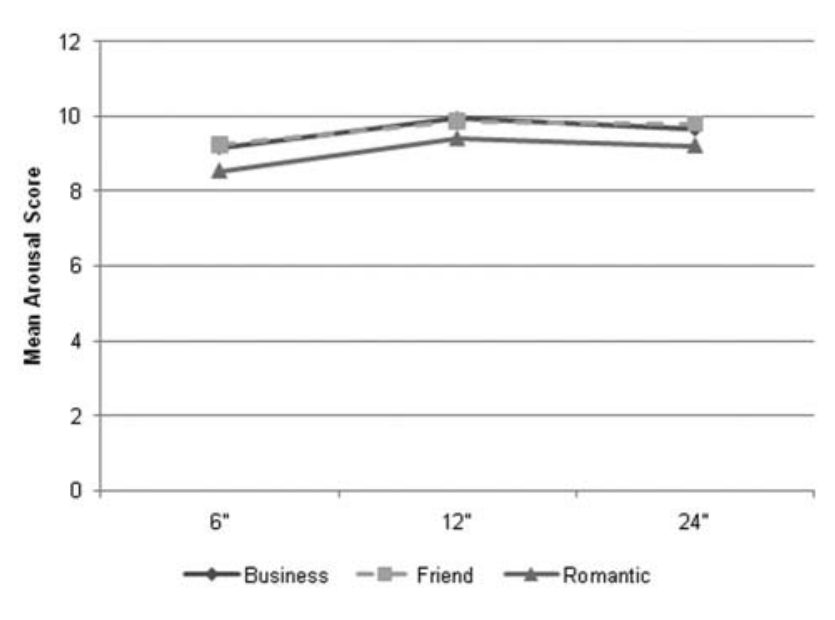

The heavy imbalance in sample sizes for the five ethnic groups tested suggested that ANOVA based on Type II sums of squares would be appropriate for determining whether differences between these groups were significant (Langsrud 2003). Stress and arousal scores were similar for all groups at each distance, but ratings of control $(F=2.979, d f=4$, $p=.018)$ and comfort $(F=3.058, d f=4, p=.016)$ varied by ethnic background. At 6 inches and 24 inches, respondents of Asian heritage felt more in control and more comfortable than other groups, whereas at 12 inches, Hispanic respondents expressed greater comfort and control. There were no other statistically significant differences across ethnic groups, and ethnicity did not interact significantly with spacing.

\section{Exhibit 13:}

Control ratings by table spacing and scenario

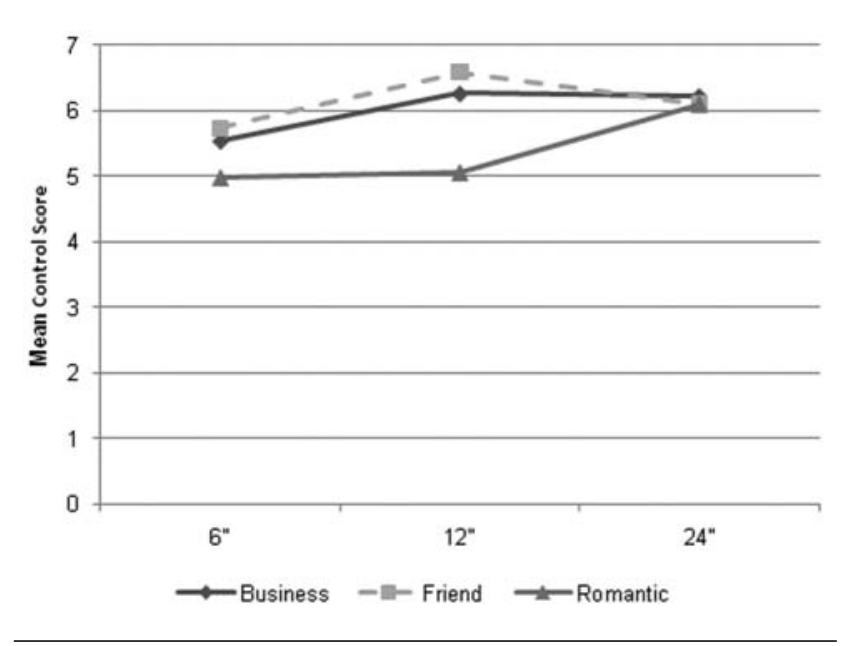

Exhibit 14:

Comfort ratings by table spacing and scenario

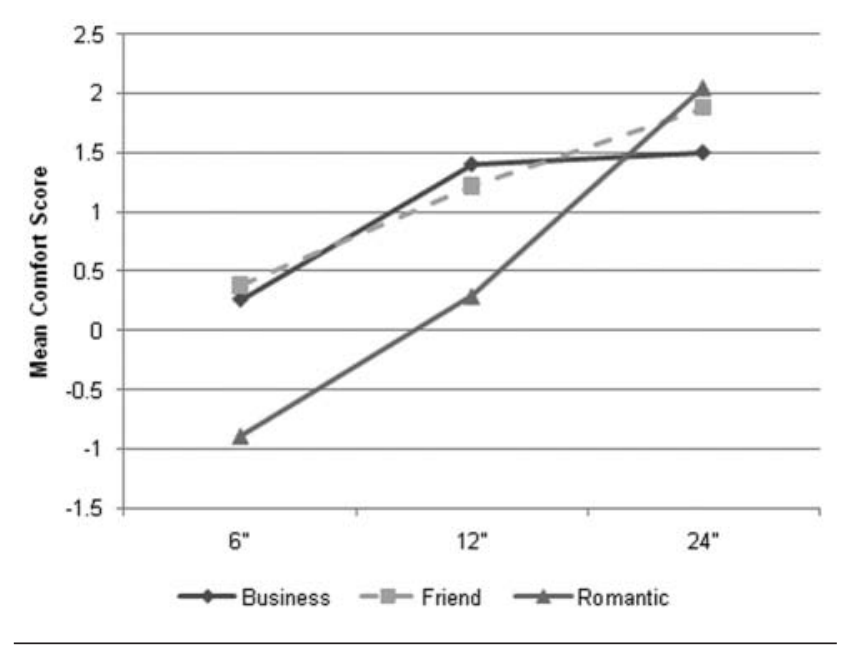

Where respondents lived did not significantly affect stress $(F=1.045, d f=4, p=.372)$, control $(F=2.187, d f=4, p=$ $.088)$, or comfort $(F=0.948, d f=4, p=.417)$, but did influence arousal $(F=3.791, d f=4, p=.010)$. Residents of large cities indicated slightly higher arousal than suburban, small town, or rural respondents at all distances but these differences were not statistically significant. Frequent diners expressed a higher degree of comfort at all table spacing distances than did those who dine out less frequently $(F=$ $3.410, d f=4, p=.009$ ), but this was the only statistically significant difference observed among all diners. Prior work experience in the restaurant industry did not have a significant effect on any measure at any distance. 
These results clearly indicate that potential restaurant guests feel strongly negative toward tables spaced as tightly as 6 inches apart, and that even the more common spacing of 12 inches is considerably less desirable than generously spaced tables.

\section{Managerial Implications and Further Research}

Consumers are clear in their dislike of closely spaced restaurant tables. When presented with images of dining tables spaced 6 inches apart, survey respondents consistently indicated that they felt uncomfortable, crowded, and generally negative toward the restaurant. Fully 70 percent of those surveyed indicated that they would be asked to be reseated if a restaurant host were to show them to a table spaced so closely to its neighbors. When tables were spaced at 12 inchesan arrangement that is not unusual in many full-service restaurants - negative responses still dominated almost every question tested. These negative reactions were similar across all dining scenarios but were most pronounced when respondents were asked to imagine they were on a romantic date.

Even at a relatively spacious 24 inches apart, parallel tables were seen as crowded and uncomfortable by 35 percent of respondents. This suggests that the use of banquettes with parallel tables may not be a good choice for many restaurants, particularly those that attract couples. Despite the spatial and operational efficiencies of banquette seating, this survey shows that many patrons find this seating to be undesirable even when the amount of space between tables far exceeds standard industry practice and the amount of personal space offered is much more generous than is typical. In practice, it has been shown that banquette seating may have a lower spending level per minute than other types of seating largely because of reductions in dining duration at these tables (Kimes and Robson 2004). This finding echoes that of a pilot study that found patrons at banquette seats rated their dining experience as significantly less pleasurable than patrons seated at freestanding parallel tables (Robson et al. 2010). This negative response to banquette seating was independent of party size, gender, and ratings of food quality or service.

Taken together, our findings suggest that banquette seating may not be the best choice for many restaurant applications (with the apparent exception of business lunches). The general antipathy toward banquette seating observed in the survey is likely to be a significant driver of shorter dining duration. Although additional research is needed to confirm and quantify this relationship, it is also true that the issue with dining duration is that of management control. From a revenue management standpoint, being able to control length of stay offers distinct operational advantages. Consequently, greater understanding of the role that table spacing plays in diner attitudes and behaviors would allow operators to set table distances to help maximize both revenue and satisfaction.
We theorized that respondents who were more likely to be familiar with tighter table spacing would be more accepting of tightly spaced tables, including those who live in expensive cities, who dine out often, or who have worked in the restaurant industry. This was not the case. Whether respondents lived in large urban areas, suburbs, small towns, or rural areas did not substantially affect their feelings about tight table spacing. Large-city dwellers indicated increased arousal at tighter distances but were equally as likely to dislike close tables. Those that dine out frequently tended to be more comfortable at closer distances but still felt stress and a lack of control when tables were only 6 or 12 inches apart. Respondents' past experience working in restaurants had no effect on any responses in our survey.

While this study only explored consumers' attitudes and preferences rather than actual dining behaviors, the findings conform to an earlier field study in a full-service restaurant that found that tables spaced more closely were less desirable and resulted in a shorter length of stay than tables that were generously spaced (Robson and Kimes 2009). In that earlier study, however, spending was not affected by table spacing. In fact, parties at the closer tables recorded a significantly higher rate of spending because of their shorter stays. This finding coupled with the results of the survey summarized here presents a conundrum for restaurant operators and designers: guests indicate that they are strongly opposed to closely spaced tables and that such spacing may significantly affect their desire to return (Robson and Kimes 2009), and yet it is possible that the shorter duration at tightly spaced tables may result in faster turns and greater revenue for the restaurateur.

Whereas current restaurant design practice routinely positions parallel tables along banquettes at approximately 12 inches apart (and even closer in expensive urban settings), it is clear that guests have a negative view of such spacing and indeed this type of seating altogether. Further research is needed to identify the optimal table spacing for creating satisfied guests while still maximizing the use of dining space. It is highly likely that the context of the dining experience and the psychographics of the target market will both moderate preferred table distances, but from these findings one can make a safe assumption that putting restaurant tables less than 12 inches apart is inadvisable if the operator hopes to please most guests, and that seating couples at banquettes regardless of the table distance is likely to result in reduced satisfaction.

While this study's findings were clear, one concern is the self-selecting nature of the respondents. As is the case with most consumer surveys, responses were voluntary and anonymous with no way to confirm the veracity of demographic responses. There are also no data on the number of prospective respondents contacted for the web survey, so a response rate cannot be gauged. The study was conducted in the United States, limiting the generalizability of its findings to other cultures. 
This study initiates a broader program of research into the most effective table spacing and table configurations for maximizing both guest satisfaction and dining room capacity. This course of research is intended to compile new evidence for proxemic preferences and behaviors in real service environments and provide the restaurant industry with guidance for effective table spacing.

\section{Appendix A}

\section{Survey Instrument}

I am: Male

Female

I am:

Under 21 years old

Between 21-35

Between 36-50

I live in:

51 years old or older

A major city (more than $1,000,000$ people)

A smaller city (more than 50,000 but less than $1,000,000$ people)

A suburban area (within twenty miles of a city with at least 50,000 people)

A rural area (no communities of more than 10,000 people within ten miles)

I am:

White/Caucasian

Black/African American

Hispanic (of any race)

Asian

Other/Mixed Race

I dine out at a sit-down restaurant:

More than three times a week

One to two times a week

One to two times a month

Less than once a month

Don't know

I have worked in the restaurant industry at some point in my life.

Yes

No

You are [on a romantic date OR having dinner with an old friend OR having a business meeting over dinner] at a nice restaurant, and have been seated at the table pictured below. [illustrated]

Please respond to the questions below based on how you would feel about being seated at this table.

Neither $\begin{array}{lcccc}\text { Strongly } & \text { Somewhat } & \text { Agree nor Somewhat } & & \text { Strongly } \\ \text { Disagree Disagree } & \text { Disagree } & \text { Disagree Agree Agree Agree }\end{array}$

Sitting at this table, I would have the
I want

I would be overheard by other diners

I would disturb the next table if I had to get up

I would have an exciting meal experience

I would feel like I was being watched

\begin{tabular}{lllllll}
1 & 2 & 3 & 4 & 5 & 6 & 7 \\
1 & 2 & 3 & 4 & 5 & 6 & 7 \\
1 & 2 & 3 & 4 & 5 & 6 & 7 \\
1 & 2 & 3 & 4 & 5 & 6 & 7 \\
1 & 2 & 3 & 4 & 5 & 6 & 7 \\
\hline
\end{tabular}




\section{Appendix A (continued)}

I would feel like a VIP

I would feel like the restaurant cares about me

I would feel exposed

Sitting at this table would make me feel:

Bothered

Contented

Uptight

Active

Comfortable

Vigorous

Distressed

Lively

Tense

Passive

Crowded

Worried

In control

Influential

$\begin{array}{ll}1 & 2 \\ 1 & 2 \\ 1 & 2\end{array}$

122

$\begin{array}{lll}1 & 2 & 3\end{array}$

123

$\begin{array}{lll}1 & 2 & 3\end{array}$

$\begin{array}{lll}1 & 2 & 3\end{array}$

$\begin{array}{lll}1 & 2 & 3\end{array}$

$\begin{array}{lll}1 & 2 & 3\end{array}$

$\begin{array}{lll}1 & 2 & 3\end{array}$

$1 \quad 2 \quad 3$

$\begin{array}{lll}1 & 2 & 3\end{array}$

$\begin{array}{lll}1 & 2 & 3\end{array}$

$\begin{array}{lll}1 & 2 & 3\end{array}$

12

1

2

Strongly

Disagree Disagree

$\begin{array}{ll}3 & 4 \\ 3 & 4 \\ 3 & 4\end{array}$

4
4
4

$\begin{array}{ll}5 & 6 \\ 5 & 6 \\ 5 & 6\end{array}$

$\begin{array}{llll}4 & 5 & 6 & 7\end{array}$

$\begin{array}{llll}4 & 5 & 6 & 7\end{array}$

$\begin{array}{llll}4 & 5 & 6 & 7\end{array}$

$\begin{array}{llll}4 & 5 & 6 & 7\end{array}$

$\begin{array}{llll}4 & 5 & 6 & 7\end{array}$

$\begin{array}{llll}4 & 5 & 6 & 7\end{array}$

$\begin{array}{llll}4 & 5 & 6 & 7\end{array}$

$\begin{array}{llll}4 & 5 & 6 & 7\end{array}$

$\begin{array}{llll}4 & 5 & 6 & 7\end{array}$

$\begin{array}{llll}4 & 5 & 6 & 7\end{array}$

$\begin{array}{llll}4 & 5 & 6 & 7\end{array}$

$\begin{array}{llll}4 & 5 & 6 & 7\end{array}$

$\begin{array}{llll}4 & 5 & 6 & 7\end{array}$

$\begin{array}{llll}4 & 5 & 6 & 7\end{array}$

\section{Neither}

Somewhat Agree nor Somewhat Strongly

Disagree Disagree Agree Agree Agree

It would be fine with me if I sat at this table If the host were to show me to this table,

$\begin{array}{lllllll}1 & 2 & 3 & 4 & 5 & 6 & 7 \\ 1 & 2 & 3 & 4 & 5 & 6 & 7\end{array}$

\section{Authors' Note}

This paper was accepted by CQ editor J. Bruce Tracey.

\section{Declaration of Conflicting Interests}

The author(s) declared no potential conflicts of interest with respect to the research, authorship, and/or publication of this article.

\section{Funding}

The author(s) received no financial support for the research, authorship, and/or publication of this article.

\section{References}

Altman, I. 1975. The environment and social behavior. Monterey, CA: Brooks-Cole.

Andersson, T. D., and L. Mossberg. 2004. The dining experience: Do restaurants satisfy customer needs? Food Service Technology 4:171-77.

Argyle, M., and J. Dean. 1965. Eye-contact, distance and affiliation. Sociometry 8:289-304.

Bailenson, J. N., J. Blascovich, A. C. Beall, and J. M. Loomis. Equilibrium theory revisited: Mutual gaze and personal space in virtual environments. 2001. Presence 10:583-98.

Barash, D. P. 1972. Human ethology: The snack-bar security syndrome. Psychological Reports 31:577-8.
Baum, A., J. D. Fisher, and S. K. Solomon. 1981. Type of information, familiarity, and the reduction of crowding stress. Journal of Personality and Social Psychology 40:11-23.

Baum, A., and S. Valins. 1977. Architecture and social behavior: Psychological studies of social density. Hillsdale, NJ: Lawrence Erlbaum.

Clark, T. 1990. International marketing and national character: A review and proposal for an integrative theory. Journal of Marketing 54:66-79.

Dale, F. D. 1982. Patterns of preference in the indoor environment. Unpublished honors thesis, University of Michigan, Ann Arbor, MI. Cited in Waxman, Lisa. 2006. The coffee shop: Social and physical factors influencing place attachment. Journal of Interior Design 31:35-53.

Desor, J. A. 1972. Toward a psychological theory of crowding. Journal of Personality and Social Psychology 21:79-83.

Donovan, R. J., J. R. Rossiter, G. Marcoolyn, and A. Nesdale. 1994. Store atmosphere and purchasing behavior. Journal of Retailing 70:283-94.

Evans, G. W., S. J. Lepore, and K. M. Allen. 2000. Cross-cultural differences in tolerance for crowding: Fact or fiction? Journal of Personality and Social Psychology 79:204-10.

Grazian, D. 2007. The girl-hunt: Urban nightlife and the performance of masculinity as collective activity. Symbolic Interaction 30:221-43. 
Hall, E. T. 1966. The hidden dimension. New York: Doubleday.

Hayduk, L. A. 1981. The shape of personal space: An experimental investigation. Canadian Journal of Behavioral Science 13:87-93.

Hayduk, L. A. 1983. Personal space: Where we now stand. Psychological Bulletin 94:293-335.

Hui, M. K., and J. E. G. Bateson. 1991. Perceived control and the effects of crowding and consumer choice on the service experience. Journal of Consumer Research 18:174-84.

Kaya, N., and F. Erkip. 1999. Invasion of personal space under the condition of short-term crowding: A case study of an automatic teller machine. Journal of Environmental Psychology 19:183-9.

Kaya, N., and M. J. Weber. 2003. Cross-cultural differences in the perception of crowding and privacy regulation: American and Turkish students. Journal of Environmental Psychology 23:301-9.

Kimes, S. E. 2004. Restaurant revenue management: Implementation at Chevys Arrowhead. Cornell Hotel and Restaurant Administration Quarterly 45:52-67.

Kimes, S. E., R. B. Chase, S. Choi, P. Y. Lee, and E. Ngonzi. 1998. Restaurant revenue management: Applying yield management to the restaurant industry. Cornell Hotel and Restaurant Administration Quarterly 39:32-39.

Kimes, S. E., and S. K. A. Robson. 2004. The impact of table characteristics on dining duration and spending. Cornell Hotel and Restaurant Administration Quarterly 45:333-46.

King, M. G., G. D. Burrows, and G. V. Stanley. 1983. Measurement of stress and arousal: Validation of the stress/arousal adjective checklist. British Journal of Psychology 74:473-79.

Knowles, E. S., B. Kreuser, S. Hass, M. Hyde, and G. E. Schuchart. 1976. Group size and the extension of social space boundaries. Journal of Personality and Social Psychology 33:647-54.

Langsrud, O. 2003. ANOVA for unbalanced data: Use Type II instead of Type III sums of squares. Statistics and Computing 13:163-67.

Lee, J. A. 2000. Adapting Triandis' model of subjective culture and social behavior relations to consumer behavior. Journal of Consumer Psychology 9:117-26.

Mattila, A. S., and J. Wirtz. 2006. Arousal expectations and service evaluations. International Journal of Service Industry Management 17:229-44.

Mehrabian, A., and S. G. Diamond. 1971. Seating arrangement and conversation. Sociometry 34:281-89.

Mehrabian, A., and J. A. Russell. 1974. An approach to environmental psychology. Cambridge, MA: MIT Press.

National Restaurant Association. Restaurant Industry Pocket Factbook 2010. www.restaurant.org/pdfs/research/2010Forecast _PFB.pdf (accessed March 13, 2010).

Patterson, M. L., C. E. Kelly, B. A. Kondracki, and L. J. Wulf. 1979. Effects of seating arrangement on small-group behavior. Social Psychology Quarterly 42:180-85.

Pedersen, D. M. 1994. Privacy preferences and classroom seat location. Social Behavior and Personality 22: 393-98.

Robson, S. K. A. 2008. Scenes from a restaurant: Privacy regulation in stressful situations. Journal of Environmental Psychology 28:373-78.
Robson, S. K., S. E. Kimes, F. D. Becker, and G. W. Evans. 2010. Responses to reduced personal space between dyads at table seating. Working paper, Cornell University, Ithaca, NY.

Rohlfs, K. V. 2009. The role of space in revenue management. PhD dissertation, Cornell University.

Sinha, S. P., and P. Nayyar. 2000. Crowding effects of density and personal space requirements among older people: The impact of social support and self-control. Journal of Social Psychology 140:721-28.

Smithers, R. 2010. Table-turning is bad manners, diners say. The Guardian, September 2, 2010. http://www.guardian.co.uk/ (accessed September 3, 2010).

Sommer, R. 1959. Studies in personal space. Sociometry 22:247-60.

Sommer, R. 1965. Further studies of small group ecology. Sociometry 28:337-48.

Sommer, R. 1969. Personal space: The behavioral basis of design. Englewood Cliffs, NJ: Prentice Hall.

Sundstrom, E. 1975. An experimental study of crowding: Effects of room size, intrusion, and goal blocking on nonverbal behavior, self-disclosure, and self-reported stress. Journal of Personality and Social Psychology 32:645-54.

Tse, A. C. B., L. Sin, and F. H. K. Yim. 2002. How a crowded restaurant affects consumers' attribution behavior. International Journal of Hospitality Management 21:449-54.

Wirtz, J., A. S. Mattila, and R. L. P. Tan. 2000. The moderating role of target-arousal on the impact of affect on satisfaction: An examination in the context of service experiences. Journal of Retailing 76:347-65.

\section{Bios}

Stephani K. A. Robson, PhD, is a Senior Lecturer in the School of Hotel Administration at Cornell Unviersity. Her research focuses on how hospitality environments influence guest preferences and behavior. She has published in the Journal of Environmental Psychology and the Cornell Hospitality Quarterly as well as presented her work to academic and industry audiences in India, Brazil, Singapore, Canada, and throughout the US.

Sheryl E. Kimes, PhD, is the Singapore Tourism Board Distinguished Professor in Asian Hospitality Management at the School of Hotel Administration at Cornell University. A leading authority in revenue management for the hospitality industry, she has published over 50 articles in leading journals such as Interfaces, Journal of Operations Management, Journal of Service Research, Decision Sciences, and the Cornell Hospitality Quarterly.

Franklin D. Becker, $\mathrm{PhD}$, is a Professor in Design and Environmental Analysis in the College of Human Ecology at Cornell University. Professor Becker is a Fellow of the American Psychological Association and a member of the International Facility Management Association. He speaks often nationally and internationally on issues related to innovative workplace strategies and evidence-based healthcare design. 
Gary W. Evans, PhD, is a Professor in Design and Environmental Analysis in the College of Human Ecology at Cornell University and is a former member of the MacArthur Foundation Network on Socioeconomic Status and Health and currently serves on the Board of Children, Youth, and Families for the National Academy of Sciences. He is the 1997 recipient of the EDRA Career Award and Past-President of the Division of Environmental Psychology of the International Association of Applied Psychology. 